\title{
Effect of breast-feeding on plasma cholesterol weight in young adults
}

\author{
M. G. MARMOT AND C. M. PAGE \\ From the Department of Medical Statistics and Epidemiology, London School of Hygiene and Tropical \\ Medicine
}

\author{
ELIZABETH ATKINS AND J. W. B. DOUGLAS \\ From the MRC Unit on Environmental Factors in Mental and Physical Illness *
}

SUMMARY The relation between breast-feeding and plasma cholesterol level in adult life was examined in a longitudinal study of a sample of people born in 1946. One hundred and seventy-two subjects whose breast-feeding history had been recorded during infancy were examined when they were 32 years old. Women who had been breast-fed had significantly lower mean plasma cholesterol than women who had been bottle-fed $(5.4 \mathrm{mmol} / \mathrm{l}$ compared with $5.9 \mathrm{mmol} / 1)$. Forg men the difference was smaller and not significant. An unexpected finding was the higher mean weight and skinfold thickness in men who had been breast-fed. These results support the hypothesis that factors acting very early in life affect the risk of disease in adults.

Plasma cholesterol levels in adults are influenced to some extent by changes in dietary composition. ${ }^{1}$ However, substantial variations between individuals are unexplained. There is evidence that atherosclerosis may begin in childhood, thus pointing to the influence of genetic or early environmental factors, and it is possible that adult levels of plasma cholesterol are influenced by early infant nutrition. In particular it has been suggested that breast-feeding may retard the process of atherosclerosis. ${ }^{2}$

This study was designed to test the hypothesis that plasma cholesterol levels in adults who have been breast-fed are lower than in adults who have been bottle-fed. The opportunity to carry out the study was provided by the National Survey of Health and Development (the 1946 birth cohort)-a longitudinal study of a national sample of all persons born in the first week of March 1946. The breast-feeding status of all the individuals in that study was recorded in May 1946 and again retrospectively in 1948. In addition, a large number of biological and social measurements were recorded in subsequent years. We examined a sample of the survey members in 1978 when they were aged 31-32 and determined their levels of plasma cholesterol and other coronary risk factors. These results form the subject of the present report.

\section{Material and methods}

In 1946, the National Survey consisted of 536 newborns. These were all the legitimate singletons born in the first week of March to parents in non-manual or farming occupations and a $25 \%$ sample of those born to manual workers. By 1972 , 867 had emigrated or died. Of the remainder, 3958 $(88 \%)$ were still under surveillance.

In order to select two distinct groups for this study, the 'breast-fed' group was defined as those survey members who had been exclusively breast-fed for the first five months of life. The 'bottle-fed' group had not been breast-fed at all during the first five months. For reasons of convenience, the study sample was restricted further to survey members living in Greater London and adjacent areas and to Bristol.

In all, 238 individuals fulfilled both the feeding and residential requirements and could be contacted in 1977. These 238 individuals were invited to participate in a special medical examination and 172 were examined, a response of $72 \%$. Of these, 155 were resident in and around Greater London and 17 in Bristol.

All examinations were conducted in the survey members' homes by one of two examiners. The examination included a questionnaire, height,

- The unit closed in September 1979. Work on the National Survey of Health and Development is continuing in Bristol under the direction of Professor J. Colley. 
weight, and blood pressure measurements (using a random-zero sphygmomanometer ${ }^{3}$ ) and a venepuncture. Plasma cholesterol level was determined by the cholesterol esterase method and high density lipoproteins (HDL) by the method of Carlson. ${ }^{4}$ At the time of the examination the interviewer did not know the subjects' breast-feeding status. On completion of the examination, subjects were asked if they knew whether they had been breast-fed and the answers were recorded. The two examiners were responsible for similar groups of subjects. The only consistent difference in the characteristics of the subjects examined by the two observers was a mean difference of $5 \mathrm{~mm} \mathrm{Hg}$ in the systolic and $2 \mathrm{~mm} \mathrm{Hg}$ in the diastolic blood pressures. On the assumption that this may have been an observer effect, these results were treated with caution.

Plasma cholesterol levels were adjusted for body weight using regression coefficients derived from the sample.

Nutrient intake was assessed by three 24-hour dietary histories. The first in each instance was performed by interview and the other two were completed by the subject and returned by post. Three consecutive days were assessed and the mean of the three was used as the measure of nutrient intake.

Social class was based on the Registrar General's 1970 classification. Housewives were classified by their husbands' occupations and women employed outside the home by their own occupations.

\section{Results}

Of the 172 subjects studied, 125 were solely breast-fed in the first five months of life and 47 were solely bottle-fed. This ratio of breast:bottle-fed is higher than the $1 \cdot 2$ :1 ratio observed in the whole National Survey. There were, however, marked regional differences in breast-feeding in 1946. In the north, for example, the ratio of wholly breast-fed to wholly bottle-fed was 1:1, and in Scotland it was 1:2. By contrast, in London and the south-east it was $2 \cdot 4: 1$ - close to the figure observed in our sample. In other respects the sample studied appeared similar to the National Survey population. For example, in $1946,53 \%$ of the 172 subjects' fathers were in non-manual occupations. This figure is similar to that obtained from the National Survey for London and the home counties (55\%), but the percentage is greater than that for the country as a whole (38\%).

The Figure shows the distribution of plasma cholesterol, adjusted for body weight, in men and women according to type of feeding. The distributions in the breast-fed were shifted slightly to the lower end. The means of plasma cholesterol,

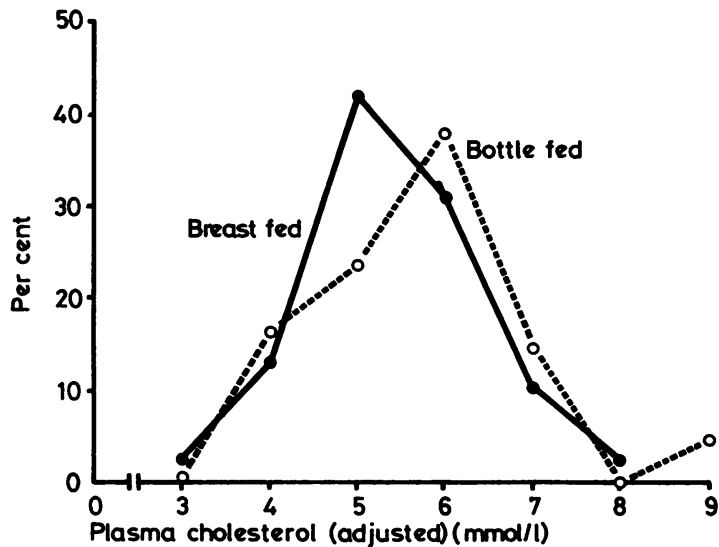

Figure Distribution of plasma cholesterol, adjusted for body.weight, in men and women according to type of feeding.

HDL cholesterol, weight, and triceps skinfold thickness are shown in Table 1. Mean plasma cholesterol was significantly lower in breast-fed than in bottle-fed women. In men the difference was not significant. There was no difference in HDL cholesterol.

Weight was significantly higher in breast-fed than in bottle-fed men, but not in women. Heights were similar in the two groups. Consequently, among men, body mass index (weight/height ${ }^{2}$ ) was higher in the breast-fed. This may have reflected a greater degree of obesity, as indicated by the greater skinfold thickness $(P=0.06)$ in the breast-fed men.

Table 1 Plasma cholesterol, body weight, and skinfold thickness in breast-fed and bottle-fed subjects. Means, and standard deviations (in brackets)

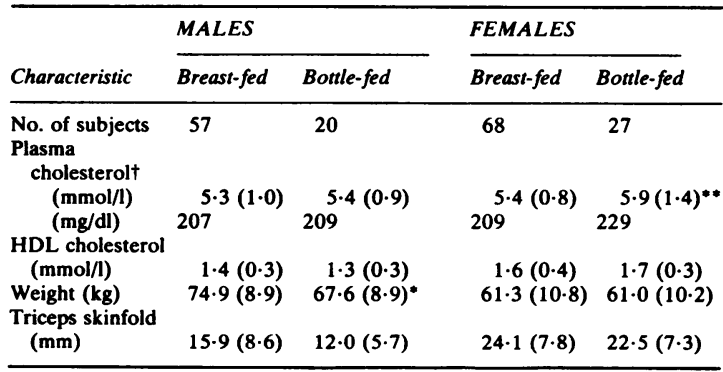

$\dagger$ Adjusted for body weight.
$\mathrm{P}<0.03$ * $\mathrm{P}<0.01$

It should be noted that the mean weight of the bottle-fed men was low $(67.6 \mathrm{~kg})$. It is possible that our sample may have been atypical. We therefore referred back to the main National Survey $(n=5362)$ to check this finding. Heights and weights had been reported by members of the survey in questionnaires completed in 1972. The self-reported 
heights and weights correlated highly with the measured heights and weights of the 172 subjects we studied.

In the National Survey proper, mean weights were higher for breast-fed than for bottle-fed subjects, and this was true both for men $(75 \mathrm{~kg}$ and $73 \mathrm{~kg}$ respectively) and for women (60 kg and $58 \mathrm{~kg}$ ).

When the blood pressures of the 172 subjects were measured, there were no consistent differences between those who had been breast-fed and those who had been bottle-fed.

\section{SOCIAL CLASS}

It is likely that subjects who had been breast-fed differed from the bottle-fed in other ways. One approach to assessing the effect of other factors on the differences observed is to examine the effects of social class. Of the subjects who had been breast-fed, $76 \%$ were engaged in non-manual occupations compared with $65 \%$ of the bottle-fed (housewives were classified according to their husbands' occupations). We therefore re-examined the data in Table 1, looking separately at those in non-manual occupations. Too few subjects were classified as manual to enable us to reach conclusions about that group. Among those classified as non-manual, the conclusions were unchanged: (a) breast-fed women had significantly lower mean plasma cholesterol $(5 \cdot 5$ $\mathrm{mmol} / \mathrm{l})$ than bottle-fed women $(6 \cdot 1 \mathrm{mmol} / \mathrm{l})$; (b) breast-fed men had higher mean weights than the bottle-fed $(74.7 \mathrm{~kg}$ and $70.0 \mathrm{~kg}$ respectively), and significantly higher body mass index.

Similar results were obtained when the subjects were classified according to their parents' occupations and education.

\section{ET}

An attempt was made to assess current nutrient intake using three 24-hour recall interviews. The results are shown in Table 2 . The breast-fed had a somewhat lower mean calorie intake. The high percentage of calories from fat was similar in the two groups, as was the $\mathrm{P} / \mathrm{S}$ ratio. Cholesterol intake was slightly higher in the breast-fed. The percentage of calories consumed as carbohydrates was also similar. None of these figures suggest that current diet explained the lower plasma cholesterol levels in the breast-fed, or the greater body weight. The percentage of calories from alcohol was marginally higher in the breast-fed group. However, the effect of alcohol is probably to raise HDL chelesterol rather than to lower total cholesterol. ${ }^{5}$

REPORTED BREAST -FEEDING

The comparison between subjects' breast-feeding status as recorded in 1946 and as reported by them in
Table 2 Nutrient intake a day in breast- and bottle-fed subjects assessed by three 24-hour dietary recalls

\begin{tabular}{lcc}
\hline Mean nutrient intake & Breast-fed & Bottle-fed \\
\hline Calories & 2188 & 2284 \\
P/S Ratio & $0 \cdot 19$ & $0 \cdot 18$ \\
Cholesterol (g) & 423 & 409 \\
Per cent calories from: & 42 & 42 \\
$\quad$ Fat & 38 & 39 \\
$\quad$ Carbohydrates & $4 \cdot 7$ & $3 \cdot 4$ \\
Alcohol & & \\
\hline
\end{tabular}

1978 is shown in Table 3 . Of those who were breast-fed for the first five months of life, $75 \%$ correctly identified themselves. By contrast, of those who were bottle-fed for the first five months, $44 \%$ did not know how they were fed and only $39 \%$ correctly identified themselves.

Table 3 Breast-feeding history as reported in 1978 survey compared with 'actual' breast-feeding as recorded concurrently in 1946

\begin{tabular}{lcc}
\hline & \multicolumn{2}{c}{ Recorded in 1946} \\
\cline { 2 - 3 } Reported in 1978 & Breast-fed & Bottle-fed \\
\hline Breast-fed & $92(75 \%)$ & $8(17 \%)$ \\
Bottle-fed & $7(6 \%)$ & $18(39 \%)$ \\
Don't know & $23(19 \%)$ & $20(44 \%)$ \\
Total & $122(100 \%)$ & $46(100 \%)$ \\
\hline
\end{tabular}

\section{Discussion}

We have shown that there is considerable error in adults' reports of whether they were breast-fed. As a result, studies that relate breast-feeding to adult health are suspect without the kind of prospective inquiry that was possible in the cohort we studied.

Before concluding that breast-feeding is associated with a lower plasma cholesterol level in adult life, we must consider in what other respects the breast-fed differed from those who were bottle-fed in our study. The breast-fed subjects were, on average, of higher social class. As plasma cholesterol was marginally higher in those in non-manual occupations, this class difference would only serve to hide a difference between breast- and bottle-fed. Thus, although family background may have influenced subsequent plasma cholesterol levels in ways other than breast-feeding, it is difficult to imagine how. There is little information available to suggest which other variables in the early environment may influence adult plasma cholesterol levels. Nor is there any documented relation between class-related genetic factors and cholesterol metabolism.

The main factor in adulthood that is likely to influence plasma cholesterol levels is dietary intake. 
The 24-hour dietary recall method has been criticised for being a crude tool. ${ }^{6}$ Although too variable to give a precise estimate of an individual's nutrient intake, it can be used as a guide to average intake for a group. In this study it provided little evidence that the diets of breast-fed and bottle-fed adults were sufficiently different to account for the lower plasma cholesterol levels in the breast-fed group.

Despite our failure to 'explain away' these lower levels, the finding must still remain tentative. Thirty-two years have elapsed between the infant feeding and the measurement of plasma cholesterol. Obviously a large number of other influences could have been acting during that time.

We have no explanation for the finding of an apparently weaker difference in plasma cholesterol among men than among women. This was not predicted and could have been due to chance. Similarly, the greater weight and body mass index among the breast-fed was unexpected. The fact that it was confirmed in the National Survey as a whole suggests that it was more than a chance occurrence, and an explanation should be sought.

In seeking an explanation for the lower plasma cholesterol, some guidance can be found in animal studies. Rats and swine breast-fed in infancy had lower plasma cholesterol levels in adult life than artificially fed animals. ${ }^{7}$ It was suggested that the high cholesterol content of breast milk sets up homeostatic mechanisms that allow the animal to metabolise cholesterol more effectively in adult life. It is unclear whether this explanation applies to the present study, because cows' milk, which formed the basis for bottle milk in 1946, contains more saturated fat than breast milk. Possibly, breast milk may not confer an advantage when compared to artificial feeds low in fat. At least one study of children aged 7-9 showed higher serum cholesterol levels in those who were breast-fed than in those fed on low-fat artificial diets. ${ }^{8}$ The low-fat diet, or the younger age of the subjects, may account for the difference from our results.
Whatever the mechanism involved, our results are consistent with an effect on cholesterol levels (and possibly, therefore, on the risk of coronary heart disease) of factors acting very early in life.

We thank Professor Geoffrey Rose, Miss Wendy McClean, and Mrs. S. L. Lo. Dr. C. Page, who was supported by a grant from the British Heart Foundation, is at present in general practice, Temple Fortune Health Centre, London N.W.11.

Reprints from Dr. M. G. Marmot, Department of Medical Statistics and Epidemiology, London School of Hygiene and Tropical Medicine, Keppel Street, London WC1E 7HT.

\section{References}

${ }^{1}$ American Heart Association. National Diet Heart Study Final Report. American Heart Association Monograph No. 18. AHA: New York, 1968.

${ }^{2}$ Osborne GR. The Incubation Period of Coronary Thrombosis. London: Butterworth, 1963.

${ }^{3}$ Rose GA, Holland WW, Crowley EA. A sphygmomanometer for epidemiologists. Lancet 1964; i: $296-300$.

4Carlson K. Lipoprotein fractionation.J. Clin Pathol 1973; suppl 26: 32-7.

${ }^{5}$ Castelli WP, Gordon T, Hjortland'MC et al. Alcohol and blood lipids. The Cooperative Lipoprotein Phenotyping Study. Lancet 1977; ii: 153-8.

${ }^{6}$ Liu K, Stamler J, Dyer A, McKeever J, McKeever P. Statistical methods to assess and minimize the role of intra-individual variability in obscuring the relationship between dietary lipids and serum cholesterol.J Chronic Dis 1978; 31: 399-418.

${ }^{7}$ Reiser R, Sidelman Z. Control of serum cholesterol homeostasis by cholesterol in the milk of the suckling rat. J Nutr 1972; 102: 1009-16.

${ }^{8}$ Hodgson PA, Ellefson RD, Elveback LR, Harris LE, Nelson RA, Weidman WH. Comparison of serum cholesterol in children fed high, moderate, or low cholesterol milk diets during neonatal period. Metabolism 1976; 25: 739-46. 